\title{
Authors at the boundary: Interaction of local and general scientific literature
}

\author{
Cigdem Baskici ${ }^{1}$, Suat Atan ${ }^{2}$ and Yavuz Ercil ${ }^{3}$ \\ ${ }^{1}$ Faculty of Health Sciences, Department of Health Care Management, \\ Başkent University, 06000, Ankara, TURKEY \\ IIndependent Researcher, TURKEY \\ ${ }^{3}$ Faculty of Communication, Department of Communication Design, \\ Başkent University, 06000, Ankara, TURKEY \\ e-mail: cbaskici@baskent.edu.tr (corresponding author); \\ suatatan@suatatan.com; yercil@baskent.edu.tr
}

\begin{abstract}
How a scientific literature is shaped both at the local and general level is an important question to answer. One practical way of achieving this task is to identify the roles played by authors (academicians) as actors creating and disseminating knowledge in the relevant literature. To this end, this study examines roles undertaken by authors in the field of learning organizations. Identifying role typologies first requires revealing the author citation network in the field. Citation network is a matrix that summarizes citations and citation numbers between authors. To construct this matrix, articles in the local and general literature in the field of learning organizations, published and indexed between January 01, 2015 and February 20, 2017, were collected from Google Scholar by using the Java-based Selenium Library. An author citation network with 19,525 actors was created from this list. A social network analysis was conducted to identify author roles, followed by a discussion of what these roles mean for the local literature. Despite defining four typologies, observing only one type of role typology indicates that the local literature is not well integrated with the general literature. This study recommends strategic assessments for increasing the contribution ability of local literature to general one. Using this approach, it would be possible to find answers to the questions of which roles to develop via which authors and relationships, and how to remove the obstacles to development of local literature.
\end{abstract}

Keywords: Author citation networks; Author role typologies; Social network analysis; Learning organizations; Web mining; Big data.

\section{INTRODUCTION}

In recent years, the network approach has been adopted in many studies to create the conceptual, intellectual and social network of specific disciplines, or fields of study (Cobo et al. 2011). Different network structures emerge depending on the actors examined and the relationship indicators between these actors (Jo et al. 2016). Author co-citation networks, co-authorship networks, and author citation networks, in particular, have been widely studied in various combinations of units of analysis and relationships. Authors are defined as actors in these networks. The authors networks may comprise other academic units such as articles, journals, institutions or patent documents (Cobo et al. 2011; Jo et al. 2016). 
In author co-citation networks, authors are the actors, and the relationships refer to the third authors' citations to the author pairs. In author co-citation networks, the strength of the relationship between a pair of authors is determined by the number of third authors that cite the same pair (García-Lillo et al. 2017). Thus, the more the authors are co-cited, the stronger the relationship between them. According to Benckendorff and Zehrer (2013), author pairs that are frequently together in the reference lists probably have something in common. It is highly probable, for example, that such pairs of authors have related ideas or methods, or the basic concepts they use are related. Depending on the study objectives, documents (Small 1973), institutions, or words (Loi, Castriotta and Di Guardo 2016) may be used as actors instead of authors. Loi, Castriotta and Di Guardo (2016) analyzed co-citation networks using articles as units of analysis, and have identified the core themes most frequently targeted in studies in the field of entrepreneurship education (1991-2014), as well as the contents of these themes and their inter-connectedness. In their study, Ferreira, Fernandes, and Ratten (2016) have created guidelines that can be used by researchers in the field of strategic management to locate their future research plans. To create these guidelines, they used co-citation analysis. Benckendorff and Zehrer (2013) used co-citation networks to visualize the relationship between the most influential authors and studies, and to identify the contributions of disciplines that supported the emergence of tourism as an academic field. Shiau, Chen, and Tsai (2015) made use of co-citation networks to unearth hidden relationships between research articles selected from leading management information systems journals. This made it possible to shed light on the intellectual structure of the field of management information systems.

In co-authorship networks, authors are the actors, and relationships are defined as collaboration between authors. The analysis of these networks can provide various insights into how research communities collaborate and evolve over time (Zervas et al. 2014). Coauthorship refers to the joint publication of a work by two or more authors (Lu and Wolfram 2012; Melin and Persson 1996). When two or more authors are listed as co-authors for the same study, it is highly probable they have collaborated in some way (Ponomariov and Boardman, 2016). Co-authorship is a measure of the relationship between authors, but compared to other measures of relationship, it indicates a stronger social connection between collaborating authors (Liu et al. 2005; Lu and Wolfram 2012). This is because author citations and co-citations can take place even when the authors do not know one another. In co-authorship, on the other hand, it is highly probable that a more social relationship exists. Lundberg et al. (2006) examined how well university-industry collaborations can be described using co-authorship data. They defined a co-authored publication as an article with at least two authors. A publication is considered to be co-authored between university and industry when at least one address in the affiliation field of the publication refers to a university, and another address refers to a company. Such publications were called interinstitutionally co-authored. Yoshikane and Kageura (2004) compared co-authorship trends in different fields of study. They defined detailed co-authorship characteristics based on the increase in the number of published articles, looking at the increase in the number of coauthorship relationships and the change in the strength of these relationships. Liu et al. (2005) examined the state of the digital library field by applying social network analysis to co-authorship networks in conferences that shaped the field of digital libraries between 1994 and 2003. They applied a variety of centrality measures to investigate this network and then defined Author-Rank, an alternative centrality metric which exploits the features of such networks.

In author citation networks, actors are the citing author and the author cited, and the relationship between the two is based on citing (Lu and Wolfram 2012). Barnett et al. (2011) used network analysis to examine citation patterns in the field of communication, between 
this field and other academic disciplines. They used journals as the unit of analysis. The relationship between journals is one of citing or being cited. Thus, a network of citations was created for communication journals. They used degree, betweenness and eigenvector centrality measures. Wang and Bowers (2016) used social network analysis to examine how knowledge is exchanged and disseminated in education administration research via journal citation networks. They used Freeman indegree and betweenness centrality measures. To analyze citations, they used author direct citation analysis. Jo et al. (2016) used journal citation networks to examine the intellectual structure and inter-disciplinary aspects of the nano field. They used a measure of centrality and brokerage analysis. Calma and Davies (2015) carried out a citation network analysis of the journal studies in higher education between 1976 and 2013. They analyzed the most published authors, most cited authors and most discussed topics.

Aforesaid citation networks and their analysis shed light on the intellectual structure of the scientific literature under study. However, previous studies did not pay much attention to the interaction between the local and general literature. Since it is necessary to clarify interaction of local and general scientific literature, we had to define local literature and general literature. In order to do it we examine the language of the articles. Literature in any local language (Turkish in this study) defines the local literature and all the other languages define the general literature. The question of which sources the literature draws on, and how, are basic questions that need to be answered to examine these interactions. In other words, which authors are able to integrate dispersed scientific knowledge and turn it into new knowledge? The present study aims to fill this gap. First, an author citation network was created for the field of learning organizations, and then, social network analysis was used to define author role typologies. These typologies are important tools that could be used to have better understanding of interaction between two levels.

This study is structured as follows. The second section provides an overview of the social network theory and explains citation network analysis. The third section provides a detailed description of the method used, and presents the results of the author citation network analysis. Then, using these results, author roles in the learning organization field are identified. The final section makes conclusions, discusses implications of the findings, and makes recommendations for future research.

\section{LITERATURE REVIEW}

\section{Social Network Theory}

Although the concept of network means different things in different fields, its definition in social sciences is important for the purposes of this study. In social sciences, a network "is a set of units comprising individuals, institutions or countries, and defines the extent, manner and direction of interconnectedness between units" (Maoz 2011, p. 7). Network structures are made up of two basic elements: actors and dyadic relationships between actors (Borgatti and Halgin 2011; Hanneman and Riddle 2005; Marin and Wellman 2014). Wasserman and Faust (1994, p. 17) define actors as "discrete individual, organizational or collective social units". According to Pryke (2012, p. 71), actor "is a term given to social entity". A relationship, on the other hand, refers to a connection between actors (Haythornthwaite 1996). Based on this basic format, various types of networks can be created by different types of actors and relationships. The type of actors and relationships are selected depending on the researcher's focus and objectives (Jo et al. 2016). 
Social network analysis treats relationships between actors as the building blocks of the social world (Pinheiro 2011), and seeks causality in the social world (structure), not among individuals (Marin and Wellman 2014). Therefore, social network analysis is about the relationships between actors (Hanneman and Riddle 2005), and is an approach that explores the exchange of resources between actors affected by these relationships, as well as their access to the resources (Haythornthwaite 1996). In more general terms, network analysis is a method that defines structures in a system on the basis of relationships between the components of the system, the analysis of which allows observing the flow of influence between components (Barnett et al. 2011).

In social network analysis, actors are usually called nodes. If there is a relationship between two nodes, the visual representation of the network displays a line between these nodes. These lines are called ties. Ties can be categorized in two ways as undirected (Figure 1a) versus directed (Figure 1.b), and dichotomous (Figure $1 \mathrm{a}$ and $1 \mathrm{~b}$ ) versus valued (Figure 1c). The direction of movement is from one node to the other in directed ties, whereas undirected ties have no direction (Marin and Wellman 2014). In dichotomous ties, the tie can be assigned one of two values: 0 or 1 . The tie is assigned the value of 0 if there is no tie between two actors, which indicates the lack of a relationship. The tie is assigned the value of 1 if there is a relationship. In the visual representation of the network, lines represent the presence or absence of a relationship between actors. They do not provide information on the strength of the relationship. Valued ties, on the other hand, have values that can be used to describe the intensity of, distance between, or costs associated with relationships (Hanneman and Riddle 2005). In other words, they provide information on the strength of a relationship.

(a)

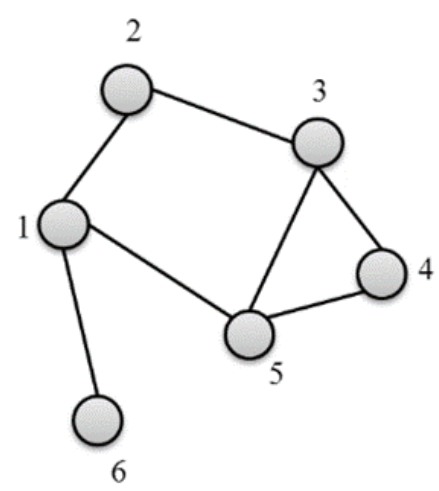

(b)

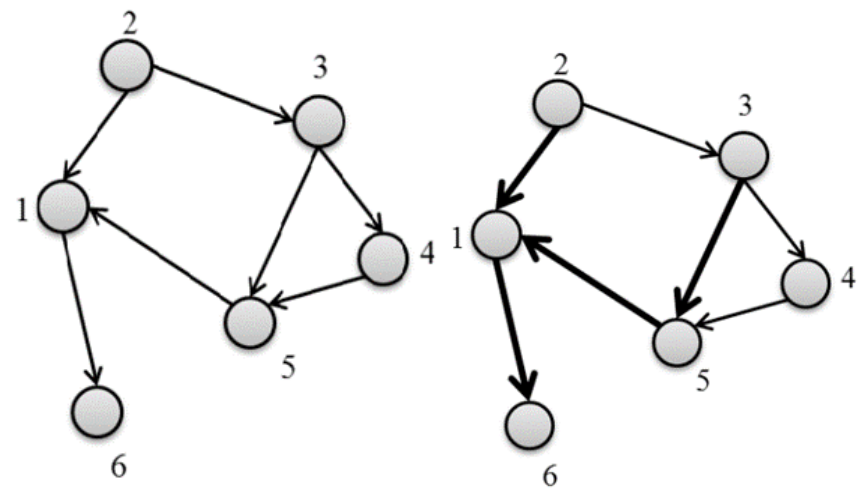

Figure 1: Categories of Ties

(c)
From the perspective of social network analysis, relationships provide a social infrastructure over which resources are transferred ( $M a$ and Yan 2016). The positions of actors in this social structure provide information about their influence on the flow of resources. An actor can have more control over the flow of knowledge, for example, compared to others, because of their position in the network. Similarly, an actor's position may allow them to have rapid access to the knowledge flow between other actors. Measures of centrality provide information about which positions confer such advantages. Four measures of centrality that are commonly used in network analysis are degree centrality, betweenness centrality, closeness centrality (Freeman 1979) and eigenvalue centrality (Bonacich 1972). 
Degree centrality is a simple but useful measure of centrality. The importance of a node can be measured by "calculating the total number of ties this node has with actors in the network, which is how degree centrality is calculated" (Ortiz-Arroyo 2010, p. 28). This calculation applies to undirected ties. In directed ties, on the other hand, two types of degree centrality are calculated: indegree centrality and outdegree centrality (Koschützki et al. 2005; Wasserman and Faust 1994). Outdegree centrality of a node equals the number of ties the node directs to others, whereas indegree centrality is the number of ties directed to the node by others (Lewis 2009). Nodes with high levels of degree centrality have "a better chance of capturing and/or directing knowledge flows in the network (Ortiz-Arroyo 2010, p. 28). In other words, high centrality indicates that the node is highly important for knowledge exchange. Therefore, these nodes, compared to nodes with lower centrality, are considered to have influence over a larger number of other nodes (Ortiz-Arroyo 2010). This study calculates indegree centrality and outdegree centrality by, respectively, counting the number of citations received and the number of citations made by authors. Thus, it would be possible to measure the importance of authors based on the number of citations they receive.

Betweenness centrality refers to "the incidence with which a given node is located between two other nodes" (Pryke 2012, p. 90). In general, betweenness centrality is defined as "the number of times a given node is needed for one node to reach another node" (Chung, Hossain, and Davis 2005, p. 6). The betweenness centrality of a node is the measure of the extent to which the node in question serves as a potential "go-between" for other nodes in the network (Balkundi and Kilduff 2006, p. 433).

Nodes with high levels of betweenness centrality can be viewed as bridges, with a high level of control over the flow of knowledge between nodes. Thus, when a node with high betweenness centrality is removed from the network, the flow of knowledge in the network may be disrupted, or reorganized as other actors have this role.

Another method to assess the importance of a node in a network is based on measuring how close the node is to every other node in the network (Ortiz-Arroyo 2010). This measure is called closeness centrality. The closeness centrality of a node is "a function of its geodesic distance (the length of the shortest route between two nodes) to all the other nodes" (Drazdilova et al. 2010, p. 305). Nodes with higher levels of closeness centrality in a network are "able to reach all the nodes in the network faster than other nodes can, and to disseminate knowledge in a shorter amount of time" (Prell 2013, p. 107). These nodes are ideally positioned to monitor knowledge flow within a network. Nodes that have more ties to nodes with higher centrality scores are considered to be more important (Prell 2013). This idea forms the basis of the measure called eigenvector centrality (Ortiz-Arroyo 2010).

Various network measures are generated as outputs of social network analysis. These measures can be at actor level, as is the case with the above explained centrality measures, or they can apply to the entire network. Analysis of the entire network results in network features that characterize the network as a whole. Network density, diameter and average path length are commonly used network-level measures. However, because they are not at actor level, they are not included in this study, which aims to identify author roles. In line with research objectives, centrality measures will be used in this study.

\section{Social Network Analysis of Author Citation Networks and Roles based on Knowledge Flow}

Studies on author citation networks employ the theoretical focus of social network theory and the analytical framework of social network analysis. Author citation networks are 
directed and valued graphs (Ding 2011; Ma and Yan 2016). In author citation networks, nodes represent authors, and directed ties represent citation relationships. The author concept represents a body of writings of an author in the selected field of study. Values assigned to ties refer to frequency of citation. These networks are subjected to comprehensive analyses in order to examine various characteristics of the intellectual structure of the scientific field, both at actor level and at network level.

Citations are used as a means of measuring knowledge transfer in author citation networks. Citations are treated as indicators of the presence, direction and amount of knowledge flow from the cited author to the citing author (Jo et al. 2016; Ma and Yan 2016). For example, if the Author A has cited the Author B five times, this is interpreted as knowledge flow of five units from the Author $B$ to the Author $A$ ( $M a$ and Yan 2016). Following citation relationships between authors thus makes it possible to examine both the routes and amount of knowledge transfer in a given scientific literature.

Because nodes represent articles or journals, instead of authors, (e.g. Barnett et al. 2011; Calma and Davies 2015; Garcia-Lillo et al. 2016; Wang and Bowers 2016) in the methodologies of the majority of existing author citation network studies, the knowledge flow described above could be defined between the articles or journals in these studies. However, in this study, articles written by multiple authors are separated so the knowledge flow can be examined among authors.

Figure 2 displays knowledge flows indicated by citation relationships between authors. In this example, the Author A cited two authors in the general literature, meaning that a flow of knowledge took place from these authors to the Author A. Knowledge flow also took place from the Author A to local authors. Lines on the figure have varying levels of thickness. The thicker a line is, the larger the number of citations between authors, and thus the amount of knowledge. This corresponds to degree centrality, one of the centrality measures that can be calculated for author citation networks using network analysis. Higher levels of indegree centrality mean that the author in question receives more citations, indicating that more knowledge flows from this author to citing authors. Moreover, authors with higher indegree scores are likely to be more influential regarding the topic, compared to authors with lower indegree scores. Higher levels of outdegree centrality mean that the author makes more citations, which is interpreted as transferring more knowledge from the surrounding authors.

Both the direction and the amount of such transfers between authors imply that authors can have different roles in the network, or in other words, in the scientific literature. Rather than adopting a holistic approach, this study assumes the presence of a dual network structure consisting of local and general levels in citation networks. This approach is based on the idea that some authors are located on the boundary between local and general literature, whereas others might be isolated from the general literature, or from the local literature. Author boundary roles to be defined from this perspective are based on degree centrality measures. There are a number of reasons for employing degree centrality when identifying author roles. The most important reason, as mentioned above, is that this measure provides knowledge about both the direction and amount of knowledge flow. When using degree centrality in the proposed dual-network structure, it becomes possible to find out whether, for example, a local author transfers knowledge mostly from the general literature, or from the local literature, and similarly, whether the author transfers knowledge to the general literature, or the local literature. Thus, it is possible to identify the authors and the roles of the authors at the boundary, which distinguishes the local literature from the general literature. It would be useful, at this point, to explain why other centrality 
measures that provide information about knowledge flows were not preferred. Betweenness centrality provides information on whether an author can stop knowledge flow in the network. In other words, betweenness centrality is a measure of the influence that an author has on the spread of knowledge through a network (Liu et al. 2005). Closeness centrality concerns how an author can affect the knowledge flow within a network (Griffin et al. 2016). Eigenvalue centrality is based on the strength of the relationship that an author has with other authors who have the capability to shape the direction and amount of knowledge flow (Barnett et al. 2011). Therefore, of the different types of centrality measures, degree centrality is the most appropriate for purposes of identifying author role typologies.

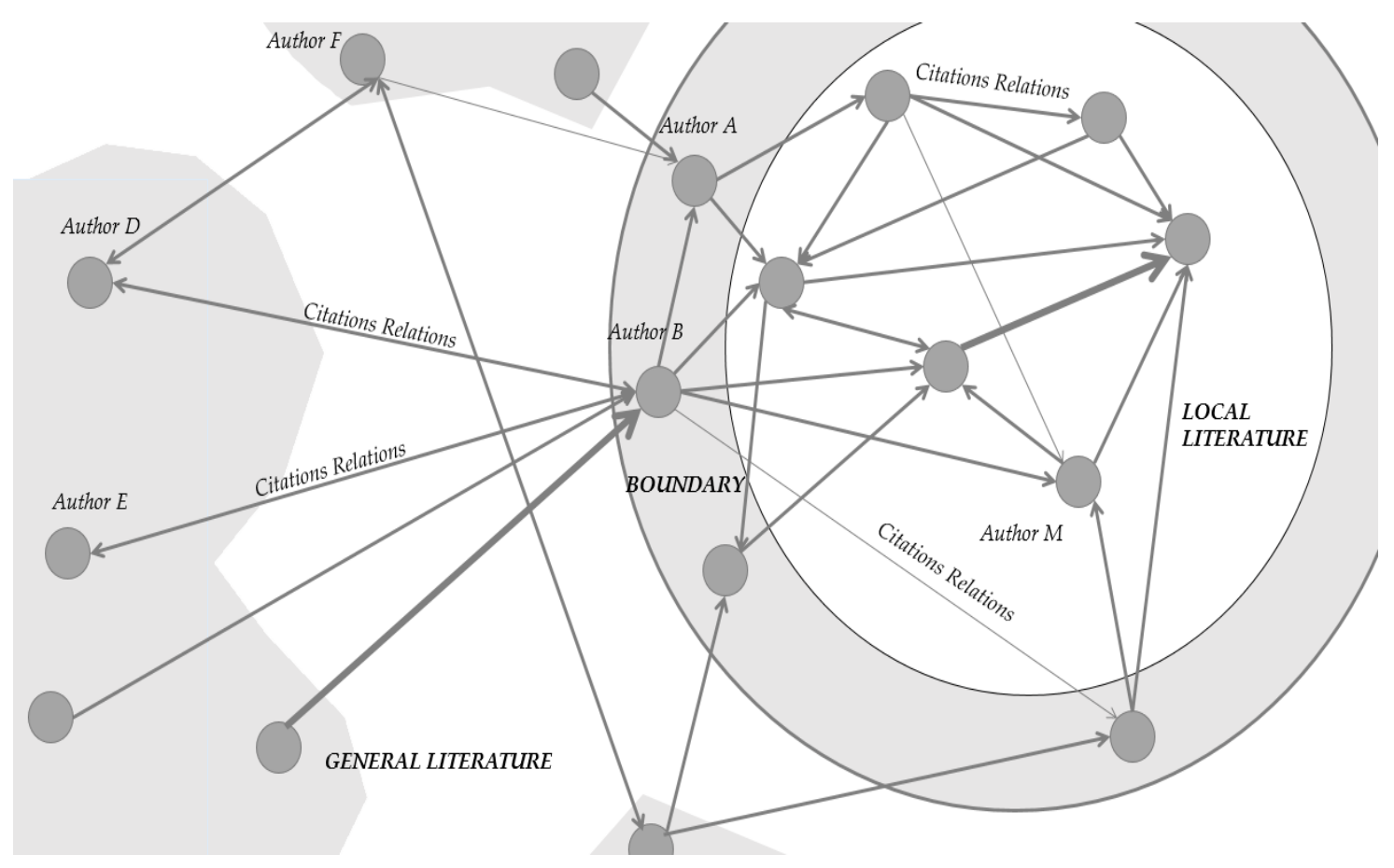

Figure 2: Knowledge Flows between Authors (Adapted from Baskici 2016)

\section{METHOD}

In business management, learning organization refers a company that facilitates the learning of its members and continuously transforms itself (Pedler, Burgogyne and Boydell 1997). The concept of learning organization is introduced to the literature by the works of Peter Senge (Senge 1990). The concept explores individual and collective learning processes in an organization. Besides the intellectual interests of the authors, the concept of learning organization can be interesting research topic in two reasons. The first reason is it is easy to follow up its evolution from the beginning since it is a new concept and known every stage in its evolution from the introducing date. The second reason is that actors dealing with the concept are well known and in reasonable numbers. It is helpful in building a network and analyzing it. To identify author role typologies in the literature on learning organizations, this study conducted a social network analysis of author citation networks. This section explains in detail the procedures followed to collect citations from Google Scholar, which was required to create the author citation networks. Then, social network analysis is used to 
calculate the degree centrality of authors in the citation networks created. Role typologies are then identified on the basis of degree scores generated.

Role typologies proposed by Baskici (2016) for actors in dual network structures were adapted for this study. Authors that are not at the boundary between local and general literature, are defined as internal authors or external authors. Internal authors operate in the local literature and have no citation connections with the general literature. These authors do not cite the general literature, nor are they cited by the general literature. In terms of degree centrality, this means that such authors have general outdegree and general indegree scores of zero. Similarly, external authors do not cite the local literature, nor are they cited by the local literature. These authors have local outdegree and local indegree scores of zero. The remaining authors can be placed at the boundary between local literature and general literature (in Figure 2: The Author A and the Author B), and can undertake one of four boundary roles (Figure 3). These roles are defined on the basis of two dimensions. The first of these dimensions is knowledge transfer. In this study, knowledge transfer is indicated by the number of citations between authors. The second dimension is the direction of knowledge transfer. This dimension is indicated by the direction of citations between the local literature and the general literature.

\section{DIRECTION OF CITATION}

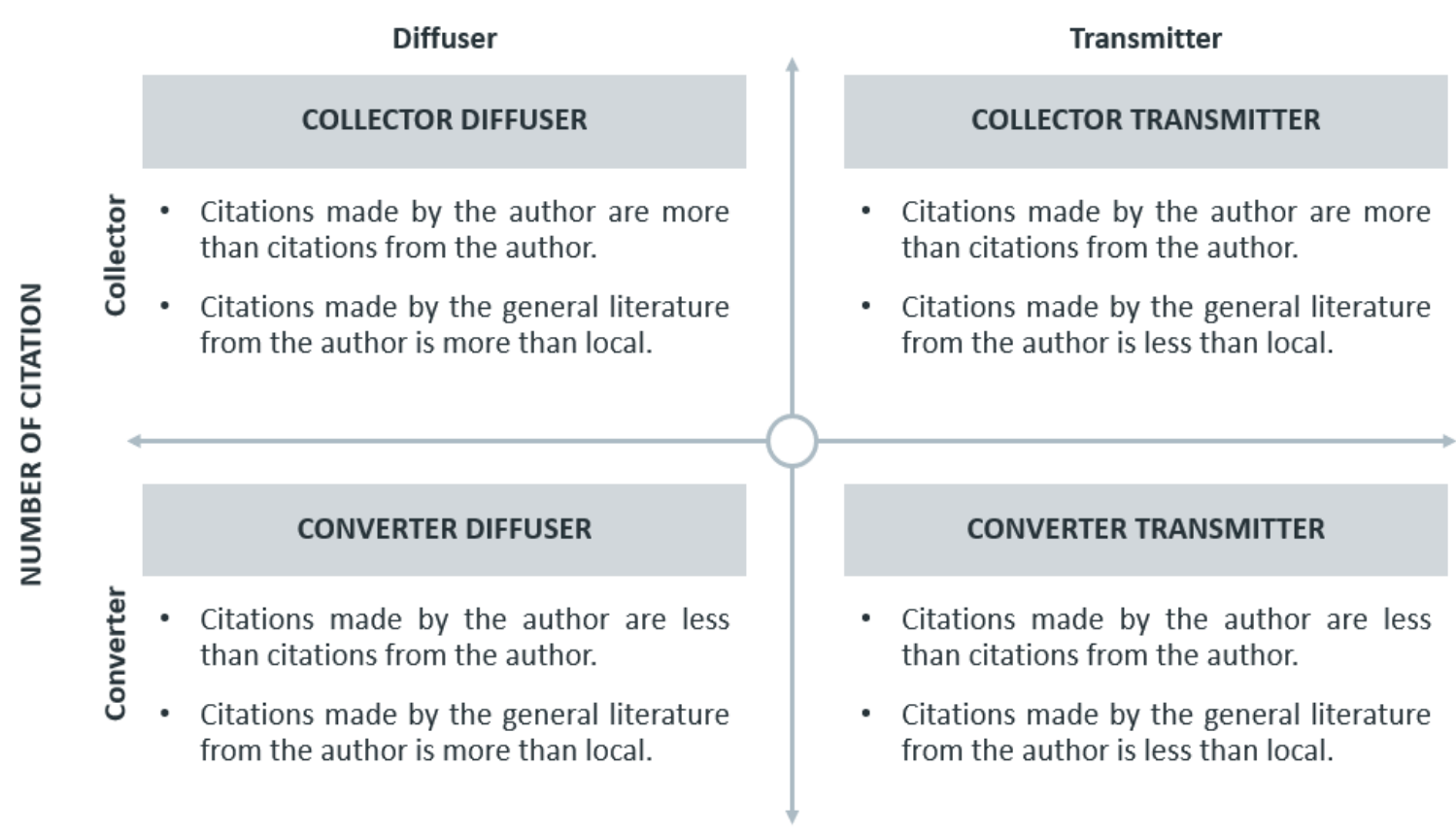

Figure 3: Author Role Typologies I: Boundary Roles

Role typologies are defined in terms of social network degree centrality metrics as depicted in Figure 4. 


\section{DIRECTION OF CITATION}

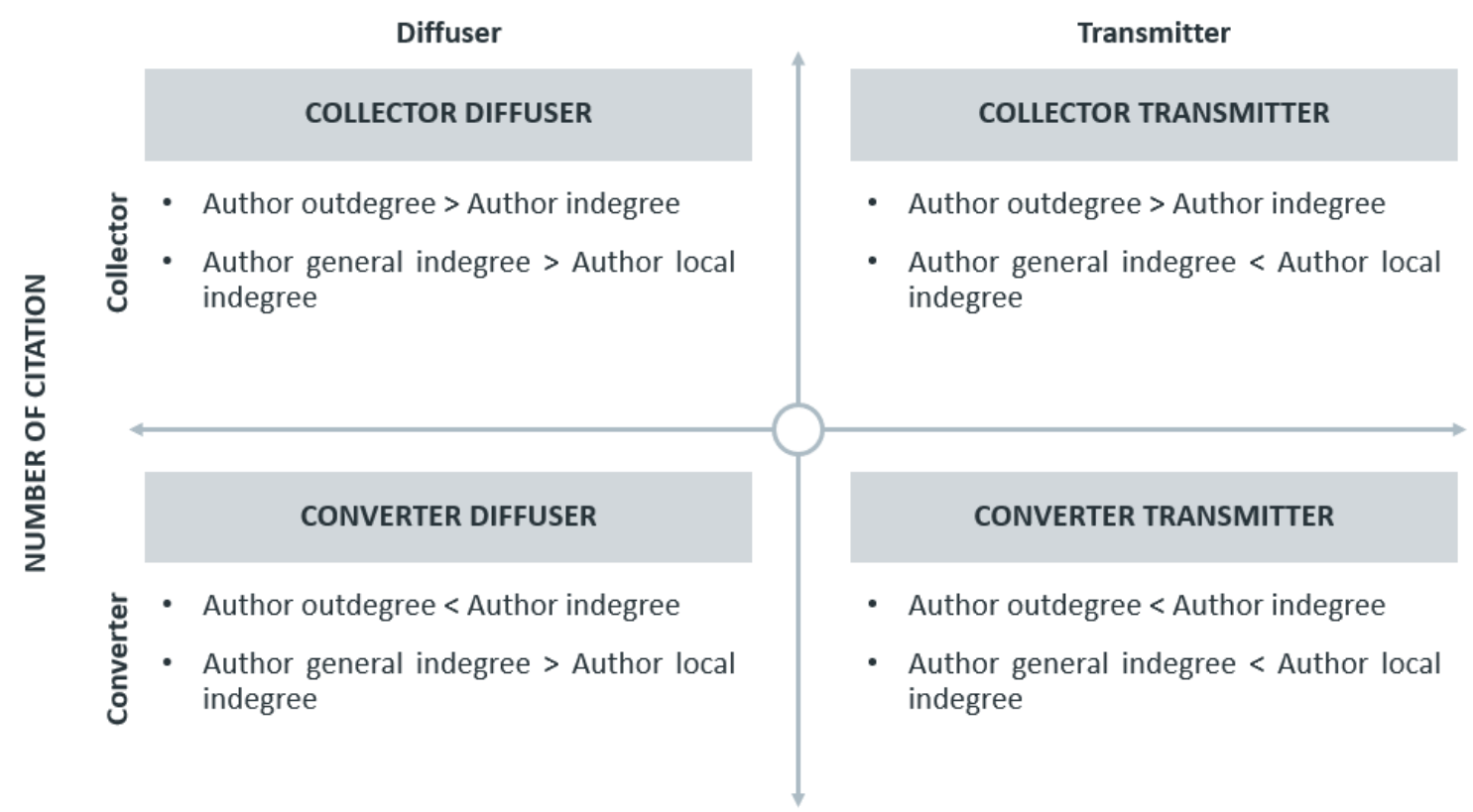

Figure 4: Author Role Typologies II: Boundary Roles

Specifically, in the article written by multiple authors, individual contribution to the scientific fields cannot be defined by existing methods in author network analysis. These methodologies are not able to identify role typologies for authors. In our method, authors are accepted as the unit of analysis. In order to define authors, articles written by multiple authors are separated. Thus, our approach differs from the existed methods in three fundamental ways. First, it is possible to analyze the individual authors' influence on the scientific literature. Second, every author in the population that contributes the scientific literature is identified. Third, it is possible to track the influences of authors' corpuses, which cannot be done in existed methods because the articles are accepted as the unit of analysis.

\section{Data Collection and Creation of Author Citation Network}

Google Scholar is preferred for this study's data collection. As is well known, it possible to access the author, date and citation information of all articles indexed by this service. In addition, the citation feature of Google Scholar, in particular, provides information about other studies that cite an article of interest. However, this dataset is not provided in group by Google Scholar. "Web scraping", a web mining method, was used to collect the dataset. Web scraping algorithm was created via the Java-based Selenium Library. All articles with the key word learning organization were collected by this method. Thus, a total of 16,530 articles and 19,525 authors indexed by Google Scholar were downloaded between January 01,2015 -February 20,2017 . This collection featured 19,525 authors, meaning that there were 19,525/16,530=1.18 authors per article. Google Scholar does not provide any information on whether or not the language of the authors is in Turkish or a language other than Turkish. Each work must be examined individually to determine the language the authors use in their scientific work. This is very difficult when considering the size of the data set. In larger data sets, manual classification may become impossible. In order to overcome this difficulty, the method of classification has been decided by machine learning algorithm which is one of the methods used in big data analysis. This method is the use of documented algorithms in an inland level of accuracy, such as the classification of any classification (for example, where a text is located), and the implementation of the big data analysis relied on 
this level of accuracy. For this purpose, languages used by authors were identified using the Textcat text classification algorithm (Cavnar and Trenkle 1994). By the help of this algorithm languages were classified using a binary label, as Turkish or non-Turkish.

After creating the database which is obtained as the result of the compilation process mentioned in Google Scholar, the process of preprocessing the data is also performed. Creation of the matrix with $19,525 \times 19,525=381,225,625$ cells was also achieved algorithmically. The data collection and processing process used to identify the citations matrix in the learning organizations literature is as shown in the Figure 5 . Details of process are described in the Appendix.

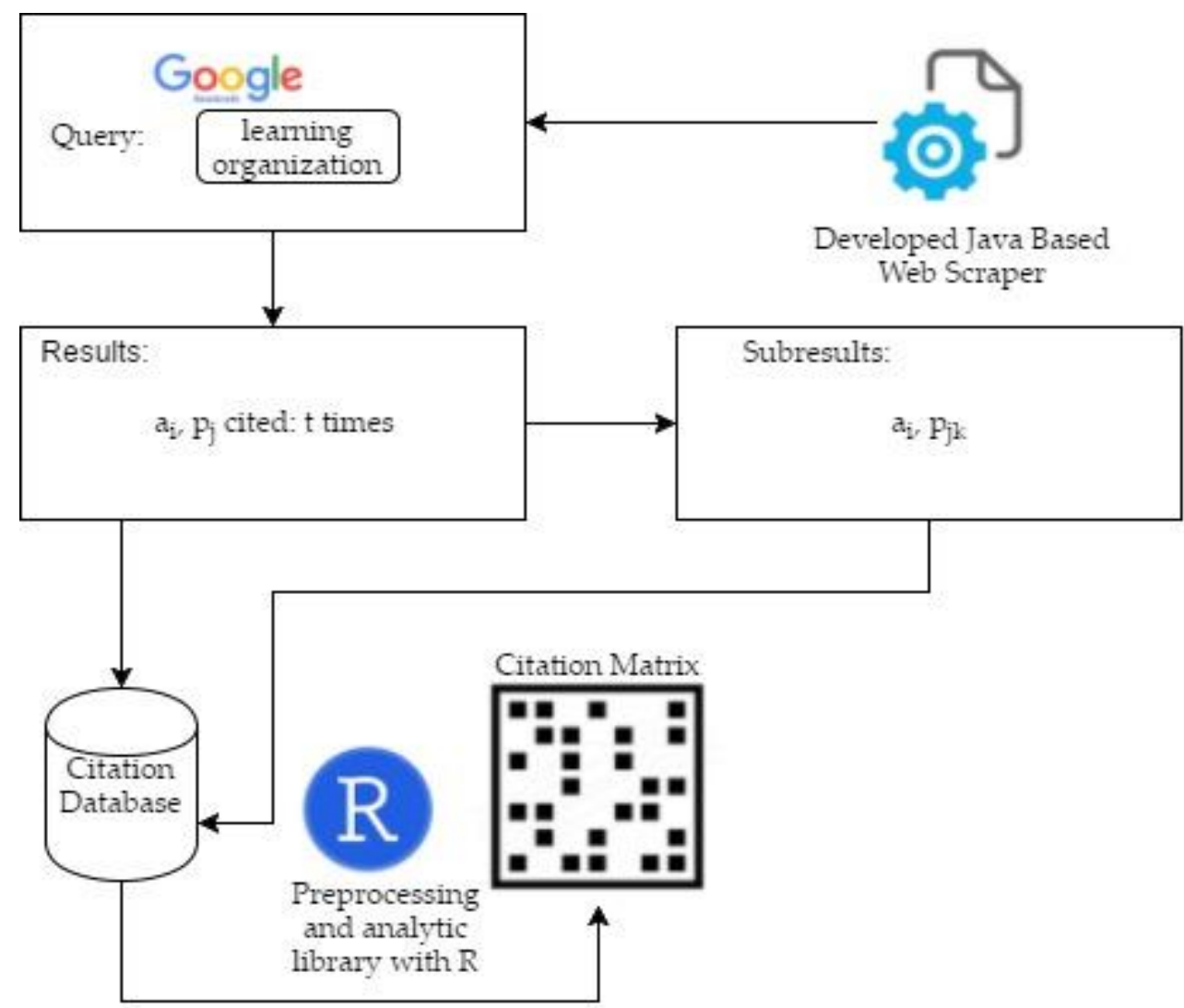

Figure 5: Data Collection and Processing Process

\section{RESULTS}

Algorithms that optimize the computer processor were used because conducting social network analysis on a matrix with $19,525 \times 19,525=381,225,625$ cells exceeds the processing power of personal computers. Local and general indegree centralities and outdegree centralities of the authors were calculated. Author role typologies are defined using these degrees ([1], [2], [3], [4]; Table 1). It was found that, of the 19,525 authors who published studies on learning organizations between January 01, 2015 and February 20, 2017, 58 were at the boundary. All of the 58 authors published their articles in non-Turkish languages, are defined as the boundary role of converter diffusers for the local Turkish literature. In the general literature on learning organizations, citations received by these authors were larger in number than the citations they made $([a+x]<[b+y])$. These authors at the boundary have come forward with their teaching qualities. Authors in this group 
should be considered the most influential group in the general literature on learning organizations.

Formula 1: Boundary roles calculation

$$
\begin{aligned}
& {[1](x+a)>(y+b) \Rightarrow \text { Collector }} \\
& {[2](x+a)<(y+b) \Rightarrow \text { Converter }} \\
& {[3] y>b \Rightarrow \text { Diffuser }} \\
& {[4] b>y \Rightarrow \text { Transmitter }}
\end{aligned}
$$

Table 1: Boundary Roles Definitions

\begin{tabular}{|l|r|c|}
\hline $\begin{array}{r}\text { Relation with local } \\
\text { literature }\end{array}$ & Transmitter & Diffuser \\
\hline $\begin{array}{l}\text { Relation with general } \\
\text { literature }\end{array}$ & {$[1] \wedge[4]$} & {$[1] \wedge[3]$} \\
\hline Collector & {$[2] \wedge[4]$} & {$[2] \wedge[3]$} \\
\hline Converter & & \\
\hline
\end{tabular}

These authors who have boundary roles received an average of 0.093 citations from the Turkish literature. On the other hand, the same authors received 34.11 citations from the general literature. None of these authors cited the local literature. They made, on average, 2.82 citations to the general literature. This study interprets the amount of citations between authors as indicating the amount of knowledge transfer. Thus, these authors were able to transfer 12.1 times the knowledge they received. This is an indicator of their ability to generate knowledge.

Of the authors with boundary roles, the top 10 that received the largest number of citations from the local literature are reported in Table 2. These authors were the actors that fed the local literature the most during the research period (2015-2017). On the other hand, Table 3 reports the top 10 authors with boundary roles that received the largest number of citations from the general literature. There is a 60 percent overlap between this list (Table 3 ) and the top ten authors list (Table 2) with the most cited from the local literature.

None of the authors in the local literature cited any of the other authors in the local literature, nor were they cited by other authors in the local literature. This shows that authors in the local literature did not engage in knowledge transfer from one another. In other words, these authors do not share their knowledge with one another. Of the authors who published in Turkish, those that made four or more citations by authors to the general literature are reported in Table 4. This table shows that an individual author in this group made a maximum of eight citations to the general literature. From 2015 to present, these authors did not form any citation relationships with Turkish articles, nor were they cited by an article in a non-Turkish. This indicates that all authors in the local literature are the end users of the knowledge they acquire. 
Baskici, C., Atan, S. \& Ercil,Y.

Table 2: The Largest Number of Citations from the Local Literature (Top 10)

\begin{tabular}{|c|c|c|c|c|l|l|}
\hline $\begin{array}{c}\text { Author } \\
\text { number }\end{array}$ & $\begin{array}{c}\text { Author } \\
\text { local } \\
\text { indegree } \\
\text { (b) }\end{array}$ & $\begin{array}{c}\text { Author } \\
\text { general } \\
\text { indegree } \\
\text { (y) }\end{array}$ & $\begin{array}{c}\text { Author local } \\
\text { outdegree } \\
(\mathbf{a})\end{array}$ & $\begin{array}{c}\text { Author } \\
\text { general } \\
\text { outdegree (x) }\end{array}$ & \multicolumn{2}{|c|}{ Boundary role } \\
\hline 414 & 6 & 524 & 0 & 7 & Converter & Diffuser \\
\hline 415 & 6 & 529 & 0 & 2 & Converter & Diffuser \\
\hline 465 & 5 & 257 & 0 & 1 & Converter & Diffuser \\
\hline 464 & 5 & 258 & 0 & 0 & Converter & Diffuser \\
\hline 162 & 4 & 723 & 0 & 12 & Converter & Diffuser \\
\hline 163 & 4 & 732 & 0 & 3 & Converter & Diffuser \\
\hline 1254 & 4 & 86 & 0 & 1 & Converter & Diffuser \\
\hline 1255 & 4 & 86 & 0 & 1 & Converter & Diffuser \\
\hline 790 & 4 & 14 & 0 & 0 & Converter & Diffuser \\
\hline 526 & 3 & 74 & 0 & 2 & Converter & Diffuser \\
\hline
\end{tabular}

Table 3: The Largest Number of Citations from the General Literature (Top 10)

\begin{tabular}{|c|c|c|c|c|l|l|}
\hline $\begin{array}{c}\text { Author } \\
\text { number }\end{array}$ & $\begin{array}{c}\text { Author } \\
\text { local } \\
\text { indegree } \\
\text { (b) }\end{array}$ & $\begin{array}{c}\text { Author } \\
\text { general } \\
\text { indegree } \\
\text { (y) }\end{array}$ & $\begin{array}{c}\text { Author } \\
\text { local } \\
\text { outdegree } \\
\text { (a) }\end{array}$ & $\begin{array}{c}\text { Author } \\
\text { general } \\
\text { outdegree (x) }\end{array}$ & \multicolumn{2}{|l|}{ Boundary role } \\
\hline 163 & 4 & 732 & 0 & 3 & Converter & Diffuser \\
\hline 162 & 4 & 723 & 0 & 12 & Converter & Diffuser \\
\hline 415 & 6 & 529 & 0 & 2 & Converter & Diffuser \\
\hline 414 & 6 & 524 & 0 & 7 & Converter & Diffuser \\
\hline 464 & 5 & 258 & 0 & 0 & Converter & Diffuser \\
\hline 465 & 5 & 257 & 0 & 1 & Converter & Diffuser \\
\hline 629 & 3 & 177 & 0 & 2 & Converter & Diffuser \\
\hline 628 & 3 & 157 & 0 & 0 & Converter & Diffuser \\
\hline 745 & 2 & 146 & 0 & 1 & Converter & Diffuser \\
\hline 7 & 2 & 127 & 0 & 4 & Converter & Diffuser \\
\hline
\end{tabular}

Table 4: Citations from the General Literature (Written in Turkish)

\begin{tabular}{|c|c|c|c|c|}
\hline $\begin{array}{c}\text { Author } \\
\text { number }\end{array}$ & $\begin{array}{c}\text { Author local } \\
\text { indegree (b) }\end{array}$ & $\begin{array}{c}\text { Author general } \\
\text { indegree (y) }\end{array}$ & $\begin{array}{c}\text { Author local } \\
\text { outdegree (a) }\end{array}$ & $\begin{array}{c}\text { Author general } \\
\text { outdegree (x) }\end{array}$ \\
\hline 2593 & 0 & 0 & 0 & 8 \\
\hline 11217 & 0 & 0 & 0 & 6 \\
\hline 13100 & 0 & 0 & 0 & 6 \\
\hline 12492 & 0 & 0 & 0 & 5 \\
\hline 6979 & 0 & 0 & 0 & 4 \\
\hline 7552 & 0 & 0 & 0 & 4 \\
\hline 12463 & 0 & 0 & 0 & 4 \\
\hline 13011 & 0 & 0 & 0 & 4 \\
\hline 13012 & 0 & 0 & 0 & 4 \\
\hline 14569 & 0 & 0 & 0 & 4 \\
\hline 16839 & 0 & 0 & 0 & 4 \\
\hline 18660 & 0 & 0 & 0 & 4 \\
\hline
\end{tabular}




\section{DISCUSSION}

Despite defining four typologies, observing only one type of role typology indicates that the local literature is not well integrated with the general literature. In addition, given that 25 years have passed since the first appearance of the term under study, this finding also indicates the speed of integration of the local literature. This indicator has multiple applications both in the scientific field in question and for the local literature. For example, integration speed of the local literature on learning organizations in different countries can be compared. Thus, countries can be ranked the in terms of their integration speed, 25 years after the coining of the term. On the other side based on this methodology it can be also possible to compare the speeds of integrations of different local literatures in the same linguistic domain. Information on which literatures are faster and which are slower in integrating would point to strengths and weaknesses of countries. It would be possible to develop strategies concerning areas of improvement for authors in the weaker literatures. It is seen that there is a $60 \%$ overlap between the lists of top 10 authors with boundary roles who received the largest number of citations from articles in Turkish and top 10 authors of boundary roles who received the largest number of citation from article in non-Turkish. This can also be interpreted as a measure of the ability of articles in Turkish to follow trends in the general literature. This ratio can be calculated for local literatures on the same topic in other countries, and their comparison would give an idea of the ability of local literatures to follow the general literature. From another perspective, it can also be compared with other fields of study in the local literature, to see which fields in the local literature have a better ability to follow the general literature. Thus, it would be possible to identify the fields of study in the local literature that have a well-developed or developing ability to follow the general literature.

The fact that all authors who have the boundary roles are in the general literature shows that sources of knowledge for local literature comes from the general literature. Thus, it can be argued that the local literature has a high level of foreign dependency. Foreign dependency indicates that the local literature has limited capacity for generating knowledge. The fact that none of the authors straddling the boundary cited authors in the local literature is arguably the biggest obstacle to the local literature gaining recognition. If this situation cannot develop, it is clear that local literature cannot have a say in general literature. There can be four main reasons behind this problem. First, the local literature might be failing to generate knowledge that is worth citing. Second, even though such knowledge would be generated, authors in the local literature might be failing to engage in knowledge-sharing. The third reason might be the limited global use of the local language. In other words, authors in the general literature not having the linguistic skills to engage with the local literature might be a problem. The fourth reason might be the significant difference in the number of authors in the local literature, and the number of authors in the general literature. The likelihood that an author seeking to cite in the general literature is likely to coincide with an author in the local literature is diminishing due to this difference. This probability has a non-linear effect because of the number of relationships.

Of the reasons mentioned above, the most important is arguably the failure to generate a sufficient amount of quality knowledge. If quality knowledge were generated, the theoretical expectation is that local authors would first share this knowledge among themselves. Then, external authors with local language will take place on the boundary between the local literature and the general literature from the moment they become aware of this knowledge accumulation and use it. These authors will have one of the roles that provide knowledge flow between local and general literature. Thus, the language barrier 
would have been overcome. Another indicator of the failure to generate sufficient knowledge is that the abstracts of all studies in the local literature are published in a foreign language as open source, yet they failed to attract the attention of the general literature. What is more, publication of abstracts in a foreign language is expected to help overcome the language barrier. Thus, if quality knowledge were generated in the local literature, this would be sufficient to negate the effects of the disparity in the number of authors, as well as the effects of the other two factors.

Acceptance and widespread use of the knowledge generated in the local literature would mean the internationalization of local literature. A prerequisite for internationalization is that local authors must have the role of converter diffusers. This is because the ability to generate original knowledge underlies the role of converter diffuser. The finding that none of the local authors have this role should be seen as an indicator of the lack of internationalization of the local literature in the field of learning organizations.

\section{CONCLUSION}

These findings indicate that examining role typologies in citation networks would make it possible to monitor the development of a specific literature and how it is shaped. In addition, this instrument would allow identifying the stage of development of this literature, developing strategies to improve the literature, and evaluating these strategies.

A limitation of the present study is that it covers a relatively short period of time. The most important reason for this limitation is the lack of data processing capability. Examining the total volume of data for 25 years of literature on learning organizations, since its inception, would require performing and evaluating billions of matrix operations. This, in turn, would require access to advanced computational hardware and additional resources. Once this limitation is overcome, author roles can be identified using a sample that would include all authors in the literature, from its inception to the present day.

\section{ACKNOWLEDGEMENT}

This research received no specific grant from any funding agency in the public, commercial, or not-for profit sectors.

\section{REFERENCES}

Balkundi, P., and Kilduff, M. 2006. The ties that lead: A social network approach to leadership. The Leadership Quarterly, Vol. 17: 419-439. Available at: http://doi.org/10.1016/j.leaqua.2006.01.001.

Barnett, G. A., Huh, C., Kim, Y., and Park, H. W. 2011. Citations among communication journals and other disciplines: A network analysis. Scientometrics, Vol. 88, no. 2: 449469. Available at: http://doi.org/10.1007/s11192-011-0381-2.

Baskici, C. 2016. Knowledge transfer in multinational companies: Role typology suggestion for embedded subsidiaries. Doctoral Thesis. Ankara University, Ankara.

Benckendorff, P., and Zehrer, A. 2013. A network analysis of tourism research. Annals of Tourism Research, Vol. 43: 121-149. Available at: http://doi.org/10.1016/j.annals.2013.04.005. 
Bonacich, P. 1972. Factoring and weighting approaches to status scores and clique identification. Journal of Mathematical Sociology, Vol. 2: 113-120. Available at: http://doi.org/10.1080/0022250X.1972.9989806.

Borgatti, S. P., and Halgin, D. S. 2011. On network theory. Organization Science, Vol. 22, no.5: 1-14. Available at: http://doi.org/10.1287/orsc.1110.0641.

Calma, A., and Davies, M. 2015. Studies in higher education 1976-2013: A retrospective using citation network analysis. Studies in Higher Education, Vol. 40, no. 1: 4-21. Available at: http://doi.org/10.1080/03075079.2014.977858.

Cavnar, W. B., and Trenkle, J. M. 1994. N-Gram-Based text categorization. Proceedings of Third Annual Symposium on Document Analysis and Information Retrieval (pp. 161-175). Las Vegas: UNLV Publications/Reprographics.

Chung, K. K., Hossain, L., and Davis, J. 2005. Exploring sociocentric and egocentric approaches for social network analysis. Second International Conference on Knowledge Management in Asia Pacific, (pp. 1-8). New Zealand: Victoria University of Wellington.

Cobo, M. J., López-Herrera, A. G., Herrera-Viedma, E., and Herrera, F. 2011. Science mapping software tools: Review, analysis, and cooperative study among tools. Journal of the American Society for Information Science and Technology, Vol. 6, no. 7: 1382-1402. Available at: http://doi.org/10.1002/asi.21525.

Ding, Y. 2011. Applying weighted PageRank to author citation networks. Journal of the American Society for Information Science and Technology, Vol. 62. no. 2: 236-245. Available at: http://doi.org/10.1002/asi.21452.

Drazdilova, P., Obadi, G., Slaninová, K., Martinovič, J., and Snášel, V. 2010. Analysis and visualization of relations in elearning. In A. Abraham, A.-E. Hassanien, and V. Snásel, Computational social network analysis: Trends, tools and research advances (pp. 291318). New York: Springer.

Ferreira, J. J., Fernandes, C. I., and Ratten, V. 2016. A co-citation bibliometric analysis of strategic management research. Scientometrics, Vol. 109, no. 1: 1-32. Available at: http://doi.org/10.1007/s11192-016-2008-0.

Freeman, L. C. 1979. Centrality in social networks conceptual clarification. Social Networks, Vol.1, no. 3: 215-239. Available at: http://doi.org/10.1016/0378-8733(78)90021-7.

García-Lillo, F., Claver-Cortés, E., Marco-Lajara, B., and Ubeda-García, M. 2017. Mapping the intellectual structure of research on 'born global' firms and INVs: A citation/co-citation analysis. Management International Review, Vol. 57, no. 4: 631-652. Available at: http://doi.org/10.1007/s11575-016-0308-5.

Griffin, D. J., Bolkan, S., Holmgren, J. L., and Tutzauer, F. 2016. Central journals and authors in communication using a publication network. Scientometrics, Vol. 106, no. 1: 91-104. Available at: http://doi.org/10.1007/s11192-015-1774-4.

Hanneman, R. A., and Riddle, M. 2005. Introduction to social network. CA: University of California. Available at: http://faculty.ucr.edu/hanneman/nettext.

Haythornthwaite, C. 1996. Social network analysis: An approach and technique for the study of information exchange. Library and Information Science Research, Vol. 18, no. 4: 323342. Available at: http://doi.org/10.1016/S0740-8188(96)90003-1.

Jo, H., Park, Y., Kim, S. E., and Lee, H. 2016. Exploring the intellectual structure of nanoscience and nanotechnology: Journal citation network analysis. Journal of Nanoparticle Research, Vol. 18: 167. Available at: http://doi.org/10.1007/s11051-016-3473-3.

Koschützki, D., Lehmann, K. A., Peeters, L., Richter, S., Tenfelde-Podehl, D., and Zlotowski, O. 2005. Centrality indices. In U. Brandes, and T. Erlebach, Network analysis: Methodological foundations (pp. 16-61). Germany: Springer.

Lewis, T. G. 2009. Network Sciences: Theory and Practice. New Jersey: John Wiley and Sons. 
Liu, X., Bollen, J., Nelson, M. L., and Van de Sompel, H. (2005). Co-authorship networks in the digital library research community. Information Processing and Management, Vol. 41: 1462-1480. Available at: http://doi.org/10.1016/j.ipm.2005.03.012.

Loi, M., Castriotta, M., and Di Guardo, M. C. 2016. The theoretical foundations of entrepreneurship education: How co-citations are shaping the field. International Small Business Journal, Vol.34, no.7: 948-971. Available at: http://doi.org/10.1177/0266242615602322S.

Lu, K., and Wolfram, D. 2012. Measuring author research relatedness: A comparison of wordbased, topic-based, and author cocitation approaches. Journal of the American Society for Information Science and Technology, Vol. 63, no. 10: 1973-1986. Available at: http://doi.org/10.1002/asi.22628.

Lundberg, J., Tomson, G., Lundkvist, I., Skar, J., and Brommels, M. 2006. Collaboration uncovered: Exploring the adequacy of measuring university-industry collaboration through co-authorship and funding. Scientometrics, Vol. 69, no. 3: 575-589. Available at: http://doi.org/10.1007/s11192-006-0170-5.

$\mathrm{Ma}, \mathrm{R}$. , and Yan, E. 2016. Uncovering inter-specialty knowledge communication using author citation networks. Scientometrics, Vol. 109, no. 2: 839-854. Available at: http://doi.org/10.1007/s11192-016-2091-2.

Marin, A., and Wellman, B. 2014. Socail network analysis: An introduction. In J. Scott, and P. J. Carrington, The SAGE handbook of social network analysis (pp. 11-25). Great Britain: SAGE.

Maoz, Z. 2011. Network of nations. The evolution, structure, and impact of international network, 1861-2001, United States of America: Cambridge University Press.

Melin, G., and Persson, O. 1996. Studying research collaboration using co-authorships. Scientometrics, Vol. 36, no. 6: 363-377. Available at: http://doi.org/10.1007/BF02129600.

Ortiz-Arroyo, D. 2010. Discovering sets of key players in social networks. In A. Abraham, A.E. Hassanien, and V. Snásel, Computational social network analysis: Trends, tools and research advances (pp. 27-47). New York: Springe.

Pedler, M., Burgogyne, J., and Boydell, T. 1997. The Learning Company: A strategy for sustainable development. 2nd Ed. London: McGraw-Hill.

Pinheiro, C. A. 2011. Social network analysis in telecommunications. New Jersey: John Wiley and Sons.

Ponomariov, B., and Boardman, C. 2016. What is co-authorship? Scientometrics, Vol.109, no. 3: 1939-1963. Available at: http://doi.org/10.1007/s11192-016-2127-7.

Prell, C. 2013. Social network analysis: History, theory and methodology. London: SAGE.

Pryke, S. 2012. Social network analysis in construction. Chichester: John Wiley and Sons.

Senge, P. 1990. The fifth dimension: The art and practice of the learning organization. New York: Currency Doubleday.

Shiau, W.-L., Chen, S.-Y., and Tsai, Y.-C. 2015. Management information systems issues: Cocitation analysis of journal articles. International Journal of Electronic Commerce Studies, Vol. 6, no. 1: 145-162. Available at: http://doi.org/10.7903/ijecs.1393.

Small, H. 1973. Co-citation in the scientific literature: A new measure of the relation between two documents. Journal of the American Society for Information Science, Vol. 24, no. 4: 265-269. http://doi.org/10.1002/asi.4630240406.

Wang, Y., and Bowers, A. J. 2016. Mapping the field of educational administration research: A journal citation network analysis. Journal of Educational Administration, Vol. 54, no. 3: 242-269. Available at: http://doi.org/10.1108/JEA-02-2015-0013.

Wasserman, S., and Faust, K. 1994. Social network analysis: Method and applications. Cambridge: Cambridge University Press. 
Yoshikane, F., and Kageura, K. 2004. Comparative analysis of coauthorship networks of different domains: The growth and change of networks. Scientometrics, Vol. 60, no. 3: 433-444. Available at: http://doi.org/10.1023/B:SCIE.0000034385.05897.46.

Zervas, P., Tsitmidelli, A., Sampson, D. G., Chen, N.-S., and Kinshuk. 2014. Studying research collaboration patterns via co-authorship analysis in the field of TeL: The case of Educational Technology and Society Journal. Journal of Educational Technology and Society, Vol. 1, no. 4: 1-16. 
The aggregation of the data from Google Scholar and the creation process of citation matrix (Figure 5) are handled in detail in the following stages. The stages are explained through the representative data.

\section{Stage 1: Obtaining raw data by web scraper}

$\begin{array}{ccc}\text { Article ID } & \text { Author(s) } & \text { Cited Article ID } \\ 1 & \mathrm{a}_{1} & 0 \\ 2 & \mathrm{a}_{2} & 1 \\ 3 & \mathrm{a}_{3}, \mathrm{a}_{4} & 2 \\ 4 & \mathrm{a}_{5} & 3\end{array}$

In the demonstrative table, the first column represents the listed articles by Google Scholar upon conducting a search with the key term. In this table, $\mathrm{a}_{\mathrm{i}}$ refers to articles' authors. The numbers in the third column indicate which articles the authors cite. For example, taking a value of 0 in the third column of $\mathrm{a}_{1}$ indicates that he does not cite any article; whereas the $a_{5}$ author takes the value 3 , indicating that this author refers to the joint article of $a_{3}$ and $a_{4}$.

\section{Stage 2: Segmentation of articles with multiple authors to articles with single author}

As the relations between the article are transformed into the relations between the authors, a question arises as to which author belongs to the scientific works written by multiple authors and to whom the constructed / given attributions belong. It is accepted that in the study the belonging in the scientific work done by multiple authors is equal and that the quoted / given citations are made separately for each article. For example, on Table 1 , authors $\mathrm{a}_{3}$ and $\mathrm{a}_{4}$ of the article with the ID no. 3 cite $\mathrm{a}_{2}$, author of the article with the ID no. 2. Each author of the article with the ID no. 3 considered the article with the ID no 2 to be an important reference and cited that article. In this way, each article with multiple authors needs to be cloned as much as the number of articles' author in order to separately define the citation relations of article with multiple authors for each author. Subsequently, article with multiple authors can be segmented into article with single author. This process was carried out and Table 1 was created.

Table 1: Citation relationship between articles

$\begin{array}{ccc}\text { Article ID } & \text { Author(s) } & \text { Cited Article ID } \\ 1 & a_{1} & 0 \\ 2 & a_{2} & 1 \\ 3 & a_{3} & 2 \\ 4 & a_{4} & 2 \\ 5 & a_{5} & 3\end{array}$

\section{Stage 3: Transforming the matrix in stage 2 into citation matrix}

The type shown in Table 1 is defined as "melted" in data science. In this way, it will not be easy to understand the relationships between the authors, since they will be duplicate writers on the line. Also, since a data set of the "melted" type will be vertical, it will not be convenient to understand the relationship. For this reason, we need to transform this data set, which is "melted", into a square matrix so that we can easily analyze the intra-network relations. For this, a matrix is created by writing an algorithm that follows the following principles: Let we have a "melted" data set like in Table 2.

Table 2: Citation relation between authors

$\begin{array}{lccc}\text { ID } & \text { Authors } & \text { Cited Article } & \text { Author of The Cited Article } \\ 1 & \mathrm{a}_{1} & 2 & \mathrm{a}_{2} \\ 2 & \mathrm{a}_{2} & 1 & \mathrm{a}_{1} \\ 3 & \mathrm{a}_{1} & 2 & \mathrm{a}_{2} \\ 4 & \mathrm{a}_{2} & 2 & \mathrm{a}_{2}\end{array}$


There would be two hypothetical authors in this data set, and four separate articles by these authors. Each row contains a citation relationship. For these citation relationships, the following steps are to be taken:

Step 1 - Create an empty matrix

An empty matrix, similar to the one shown below, is created. This empty matrix is a vector of author names with vertical and horizontal axes.

$$
\begin{array}{lll}
\cdot & \mathrm{a}_{1} & \mathrm{a}_{2} \\
\mathrm{a}_{1} & 0 & 0 \\
\mathrm{a}_{2} & 0 & 0
\end{array}
$$

Step 2 - Enter each row on the melted data set to the matrix The relationship in the first row will be expressed as follows:

$$
\begin{array}{lll}
\cdot & \mathrm{a}_{1} & \mathrm{a}_{2} \\
\mathrm{a}_{1} & 0 & 0 \\
\mathrm{a}_{2} & 1 & 0
\end{array}
$$

This matrix shows that, in the first row, author $a_{1}$ was cited one times by the author $a_{2}$. Other relationships in rows will be treated as follows:

2. relationship $a_{1} \quad a_{2}$

$\begin{array}{cll}\mathrm{a}_{1} & 0 & 1 \\ \mathrm{a}_{2} & 0 & 0 \\ \text { 3. relationship } & \mathrm{a}_{1} & \mathrm{a}_{2} \\ \mathrm{a}_{1} & 0 & 0 \\ \mathrm{a}_{2} & 1 & 0 \\ \text { 4. relationship } & \mathrm{a}_{1} & \mathrm{a}_{2} \\ \mathrm{a}_{1} & 0 & 0 \\ \mathrm{a}_{2} & 0 & 0\end{array}$

In case four, the author $\mathrm{a}_{2}$ cited themselves. However, self-citations are not counted. For this reason, the matrix will not be reflected.

Step 3 - Aggregate matrices, which equal the relationships in number in previous steps, as elementwise

In the previous steps, we can obtain the matrix of each author's citation relation by summing up the separate matrices that correspond to each table in Table 2 . When these matrices are aggregated, the following matrix emerges:

$\begin{array}{cll}\text { Aggregation } & \mathrm{a}_{1} & \mathrm{a}_{2} \\ \mathrm{a}_{1} & 0 & 1 \\ \mathrm{a}_{2} & 2 & 0\end{array}$

According to this matrix author $\mathrm{a}_{1}$ was cited twice by the author $\mathrm{a}_{2}$. On the other hand, author $\mathrm{a}_{2}$ was cited once by the author $\mathrm{a}_{1}$.

These steps involve converting network relationships which is the pre-processed "melted" dataset, compiled from Google Scholar, into square relations. Thus, a citation network is constructed in which the social network analysis can be performed. 